
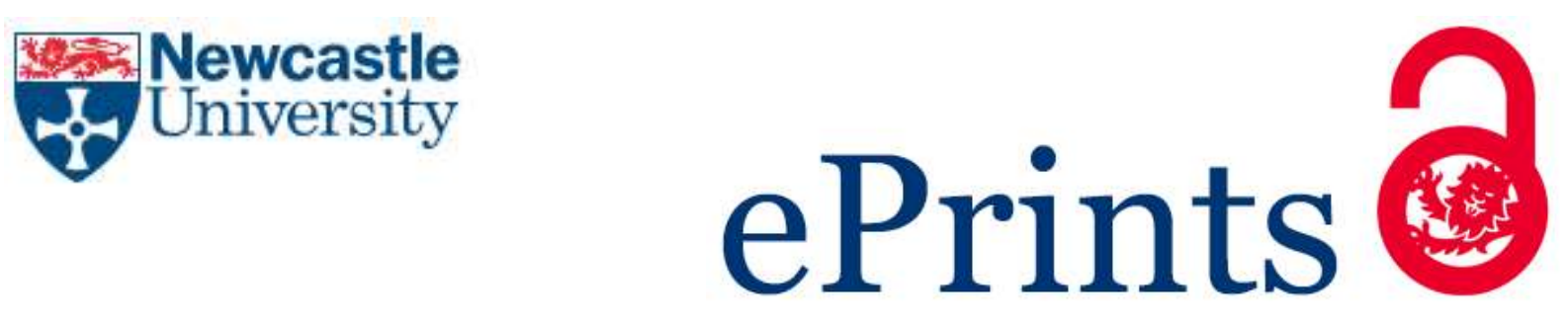

Coward T, Tribe H, Harvey AP.

Opportunities for process intensification in the UK water industry: A review. Journal of Water Process Engineering 2018, 21, 116-126.

\title{
Copyright:
}

(C) 2018. This manuscript version is made available under the CC-BY-NC-ND 4.0 license

DOI link to article:

https://doi.org/10.1016/j.jwpe.2017.11.010

Date deposited:

$27 / 03 / 2018$

Embargo release date:

23 March 2019

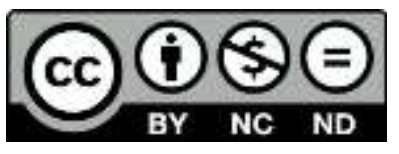

This work is licensed under a

Creative Commons Attribution-NonCommercial-NoDerivatives 4.0 International licence 


\section{Opportunities for process intensification in the UK water}

\section{2 industry: a review}

\section{Thea Coward ${ }^{1}$, Harry Tribe ${ }^{2}$, and Adam Harvey ${ }^{1 *}$}

41 School of Chemical Engineering and Advanced Materials, Newcastle University,

$5 \quad$ Newcastle Upon Tyne, NE1 7RU

62 Amec Foster Wheeler, Partnership House, Newcastle Upon Tyne, NE3 3AF

7

$8 \quad$ * Corresponding author; adam.harvey@ncl.ac.uk; Tel.: +44 (0) 1912086231

9 Abstract:

10 Process Intensification (PI) refers to the use of novel process technologies to achieve

11 significant (order of magnitude) size reduction in individual unit operations, or the complete

12 removal of process steps by performing multiple functions in fewer steps. This should lead to

13 significant reductions in capital and running costs, and improvements in process efficiency

14 and safety. There are numerous examples of PI being successfully implemented in the oil and

15 gas, pharmaceutical, food and drink, and fine chemical industries, but few in the water

16 industry. There are however a range of drivers for process intensification within the water

17 industry. These include ever more stringent environmental standards and more intractable

18 pollutants. The aim of this review was to identify PI technologies that could be used in the

19 future UK water industry, but require further technical development (to increase their TRL),

20 or transfer from other industries. Recommendations for technologies are given, as well as

21 routes to their implementation.

Highlights:

- PI can significantly reduce the size of unit operations, remove process steps and make processes more efficient and safer

- The UK water industry is facing environmental, financial, and land constraints, all of which may be drivers toward more efficient and innovative processing

- There is significant potential for the application of novel PI technologies 
29 Keywords: Process Intensification; Novel technologies; Oscillatory baffled reactors;

UV LEDs; Rotating packed bed; Fluidic oscillator devices

\section{Introduction}

33

The water industry has been notoriously slow to implement change, often embracing tradition and conservative treatment technologies (Speight, 2015; Tanner et al., 2016; Thomas, 2012; Thomas \& Ford, 2006; Thomas \& Ford, 2008). The barriers affecting the water sector's ability to adopt innovative technologies has been explored by a number authors (Speight, 2015; Spiller et al., 2015; Spiller et al., 2012; Tanner et al., 2016; Thomas, 2012; Thomas \& Ford, 2006). They found that key barriers to innovation in the UK water industry include the excessive time it takes for innovations to become adopted within the water sector, the industry's risk-averse attitudes, and a lack of knowledge about new and emerging technologies (Spiller et al., 2012; Tanner et al., 2016; Thomas, 2012; Thomas \& Ford, 2006). However, the water industry in the UK is under ever-increasing pressure to meet future water demand, alongside facing challenges due to aging infrastructure, and environmental, financial, and land constraints. The consequences of failing to meet these challenges could include environmental degradation, public health risks, and increased operational costs (Speight, 2015).

Process intensification (PI) is a chemical and process design approach that leads to substantially smaller, cleaner, safer and more energy-efficient process technology. PI technologies have successfully been adopted by innovation led industries such as petrochemical, chemical, food, and pharmaceutical (Reay et al., 2013). The aim of this review is to identify new and emerging PI technologies that could be used in the UK water industry, but require further technical development (to increase their TRL), and technologies that could be transferred from other industries. In particular, this review aims to bring a number of process technologies to greater attention within the UK water industry. It should be noted that this work has a strong focus on the UK water industry as it was funded by UKWIR (Grant No. RG10). However, the PI technologies presented in this review may also be relevant to the US, Australia and the Middle East, where traditional approaches are struggling to meet growing need. There may also be some relevance to the developing world, in that PI technologies are often a good solution when industries become distributed; 
61 decentralized PI water systems could therefore be installed based on need, removing the excessive cost of implementing centralized treatment systems (Massoud et al., 2009). The downside may be that some of the technologies are not "simple" to manufacture or maintain. The work Tayalia and Vijaysai (2012) gives insight into how PI techologies can be applied to multiple global water and wastewater scenarios, such as the increased need to process source water of increasing salinity.

The UK water and sewerage industry was privatised in 1989, and now comprises 32 privately-owned companies in England and Wales, while Scotland, and Northern Ireland operate as non-profit, semi-governmental water authorities (Ofwat, 2017; Speight, 2015). The Water Framework Directive (WFD) in the EU is an overarching legislation that came into force in 2000 and is driving technological investment in the water industry (European Communities 2000/60/EC). It is administered by the Drinking Water Inspectorate (DWI) for water and the Environment Agency (EA) for wastewater and natural water sources in England and Wales. It aims to achieve "good ecological status" in inland and coastal waters through river basin management planning. Concentration limits have been defined for 30 substances under the Environmental Quality Standards (EQSs-EC, 2008), and the UK is required to set its own standards for a further group of potential pollutants (Gardner et al., 2013). New and emerging pollutants (EPs) present a new and significant challenge to UK and global water quality. EPs originate from a wide range of man-made chemicals, such as pesticides, cosmetics, personal and household care products, and pharmaceuticals (Geissen et al., 2015). Increasing scientific evidence has demonstrated that EPs, and endocrine-disruptors (ECDs) in particular, are associated with breast cancer in women and prostate cancer in men, feminisation of male fish reducing their reproductive fitness, and can significantly affect plant growth and development (Acerini \& Hughes, 2006; Adeel et al., 2017; Gavrilescu et al., 2015; Geissen et al., 2015). Gardner et al. (2013) assessed the performance of 16 wastewater treatment plants (WwTP) to provide an overview of trace substance removal. This study highlighted significant variations in the removal rate of trace substances. This was possibly due to variation within catchments or design and operation of individual works. However, it is evident from this work that improvements in the methods used to remove trace chemicals needs to be prioritised as current methods are inconsistent. Gardner et al. (2013) concluded that in order for step changes in performance to occur, new treatment methods are required. Heightened public awareness and concern about the impacts of EPs will no doubt encourage ever stricter limits on priority substances in the near future. The WwT industry has responded 
94 by developing and implementing processes and technologies to meet these demands, with resultant increases in utility consumption, notably electrical power and treatment chemicals. These increases in treatment sophistication and energy use have led to increased carbon emissions, particularly operational carbon. The Environment Agency (UK) has stated that "without intervention, increased WwT under the WFD is likely to increase $\mathrm{CO}_{2}$ emissions by over 110,000 tonnes per year from operational energy use and emissions associated with the additional processes required" (Georges et al., 2009). They suggested five key strategies that the water industry and partners could adopt to mitigate the carbon impact of the WFD. They included increasing operational efficiencies to reduce the demand for power, and redeveloping existing treatment processes by switching from conventional processes to lower energy alternatives (Georges et al., 2009).

Regional growth of the UK is also stretching WwT sites' capacities. It is essential that the demand for new wastewater infrastructure is met to ensure water quality for public health. New infrastructure options are limited in densely populated cities where land is a premium. Some additional capacity can be provided through minor works and expansions of the sites (Defra, 2010), however, a holistic overview is required to identify robust, efficient, cost effective solutions to satisfy the greater demands of the water industry, without taking up more space.

Further to this ever-increasing treatment and legislation demand, the water industry in

113 England and Wales is also subject to economic regulation through Ofwat (The Water

114 Services Regulation Authority), which, is responsible for setting limits on pricing that the 115 water and sewage companies may levy on their customers, which in turn, puts pressure on costs, driving cost efficiencies through the industry. Ofwat has allowed the companies to invest more than $£ 130$ billion in maintaining and improving assets and services, however the total spend for R\&D for all water and wastewater industries was only $£ 18$ million in 2008 , which represents just $0.5 \%$ of annual turnover (CST, 2009; Ofwat, 2017; Tanner et al., 2016). embraces innovation and invests in research. The country has transformed from having little centralized sanitation and reliance on imported water from Malaysia, to a world-leading research and development 'hydrohub' over the past 50 years (Speight, 2015). 
127 Water treatment systems commonly depend on complex interactions between mass transfer and various physical, biological, and chemical processes (Owabor, 2013). Water treatment systems are currently dependent on relatively low capital intensity technologies, often relying

130 on stirred or contact tanks systems for processes such as chlorination, anaerobic treatment,

131 the addition of flocculants etc. However, a key issue in these systems is effective mixing,

132 which is technically very difficult at large scales. This means that many processes are

133 mixing-limited (Reay et al., 2013). Therefore, the understanding of mass transfer mechanisms

134 enables the proper design and operation of many processes (Zhou \& Smith, 2000). Process

135 intensification (PI) is the philosophy that many unit operations, and entire processes, can be

136 substantially improved by novel equipment, processing techniques and operational methods

137 (Stankiewicz \& Moulijn, 2000). These new technologies have on the whole been developed

138 by re-examining the assumptions involved in the heat transfer and/or mass

139 transfer/mixing/fluid mechanics in conventional technologies (Górak \& Stankiewicz, 2011;

140 Nikačević et al., 2012; Ponce-Ortega et al., 2012; Reay et al., 2013). This can result in

141 significant (order of magnitude) reductions in equipment size, and/or substantial reductions in

142 the number of steps in a process by performing more than one function in one step.

143 Colin Ramshaw and colleagues at Imperial Chemical Industries (ICI) pioneered the 144 concept of PI during the late 1970s, where the primary goal was to reduce the capital cost of 145 production systems (Dautzenberg \& Mukherjee, 2001; Ramshaw, 1983; Reay et al., 2013).

146 They defined PI as the "strategy of making significant reductions in the size of unit 147 operations, while achieving a given production objective" (Dautzenberg \& Mukherjee, 2001).

148 Since that time, there are many examples of intensified technologies being successfully 149 applied, in industries such as petrochemical (Harmsen, 2010), chemical (Stankiewicz \& 150 Moulijn, 2000), food (Patist \& Bates, 2008; Wang et al., 2017a), and pharmaceuticals

151 (Buchholz, 2010). Figure 1 illustrates the broad range of technologies that are considered 152 “intensified" (but this is by no means comprehensive). 


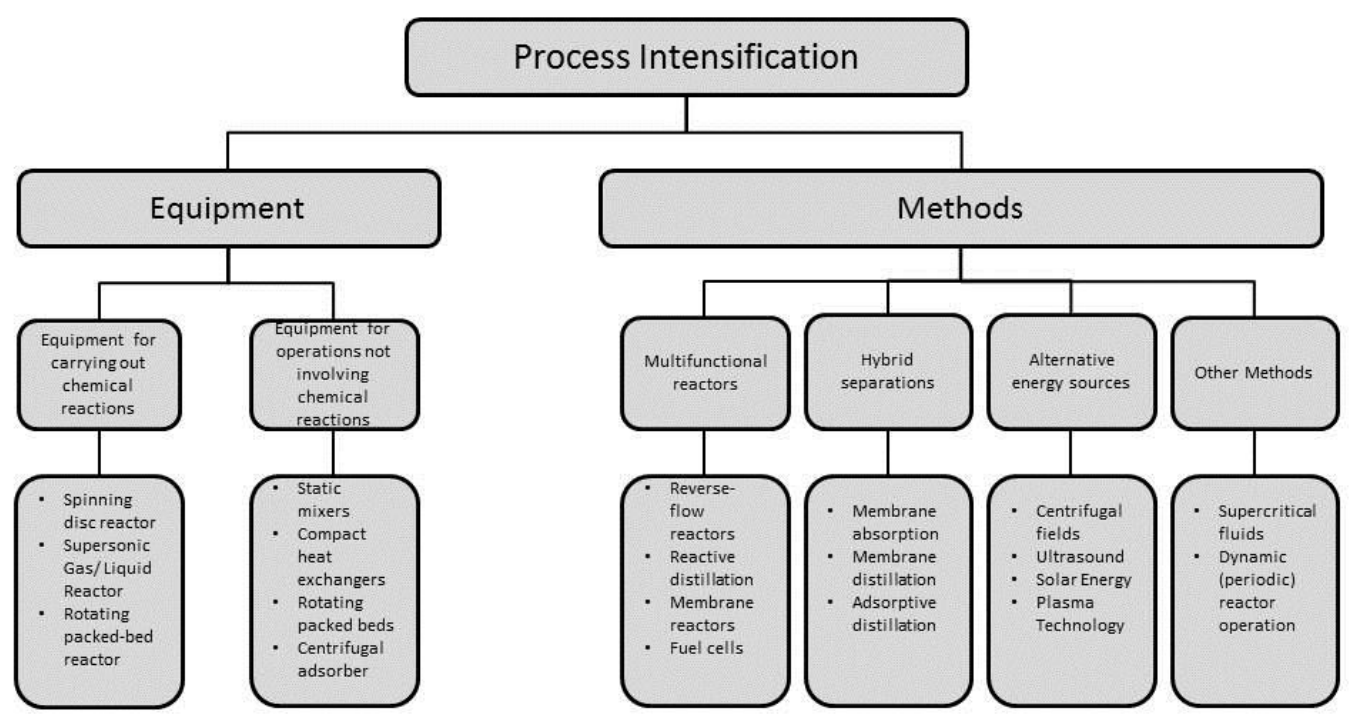

154 Figure Error! No text of specified style in document.. Examples of the broad uses of Process

155 Intensification equipment and methods. The diagram has been adapted from Process

156 intensification classification by Stankiewicz and Moulijn (2000).

Górak and Stankiewicz (2011) defined four "multi-scale domains" to classify the

159 applications of PI: spatial, thermodynamic, functional, and temporal (Table 1). Utilising one

160 or more of these domains to design new plants, retrofit existing units, or implement new

161 processing methods can lead to the process being more efficient, safer, flexible, smaller,

162 cheaper and more environmentally friendly (Charpentier, 2007; Ponce-Ortega et al., 2012).

163 Development of new chemical routes, even if achieving a dramatic improvement in

164 processing does not qualify as PI, as PI is specifically based upon new process technologies

165 rather than new chemistry (Stankiewicz \& Moulijn, 2000).

166

167 Table 1: The four fundamental domains, main approaches and their associated motivations of 168 process intensification (PI) (Górak \& Stankiewicz, 2011)

\begin{tabular}{lll}
\hline Domain & Main PI approach & Motivation \\
\hline Spatial & Structured environment & -Well-defined geometry \\
& -Creation of maximum specific surface area at \\
& minimum energy expenses \\
& -Creation of high mass and heat transfer rates \\
& -Precise mathematical description
\end{tabular}




\begin{tabular}{lll}
\hline & & -Easy understanding, simple scale-up \\
Thermodynamic & Alternative forms and & -Manipulation of molecular orientation \\
& transfer mechanisms of & -Activating/moving targeted molecules \\
energy & -Selective, gradientless, and local energy supply \\
Functional & Integration of & -Synergistic effects \\
& functions/steps & -Better energy management \\
& & -Increase of overall efficiency \\
& Timing of the events, & -More compact equipment \\
introducing dynamics & -Controlled energy input \\
(pulsing) & -Increased energy efficiency \\
& -Minimization of unwanted phenomena, such as \\
& fouling \\
\hline
\end{tabular}

172 are fundamentally similar (Reay et al., 2013). PI technologies and methods could therefore be

173 adopted into the water and wastewater industries where they perform similar duties in other 174 industries.

175 Figure 2, below, summarises how PI technologies can: reduce energy consumption,

176 reduce foot-prints, potentially generate value from waste, allow for more flexible processing

177 to meet varying feed qualities, improve trace chemical removal, reduce the time to market,

178 reduce life-cycle costs, and a combinations of these objectives (Tayalia \& Vijaysai, 2012). 


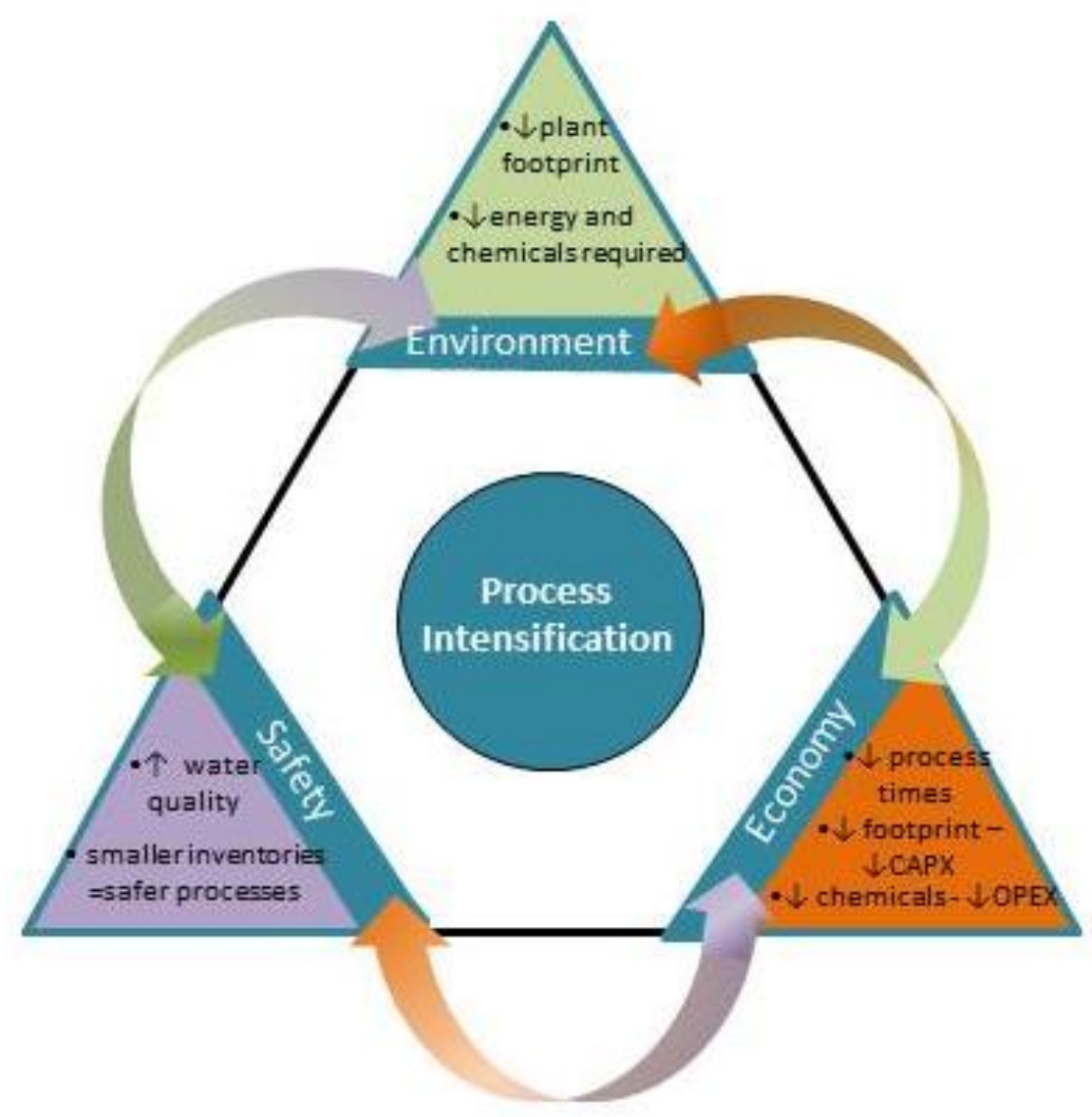

180 Figure 2: The potential impact of intensified process technologies on key areas in the water 181 industry.

\section{Novel PI technologies for the UK water industry}

184

185 A range of 'scoring criteria' were developed to provide a framework for assessing PI

186 technologies. The evaluation criteria were: capital cost, operating cost, whole life cost,

187 performance, sustainability, foot-print, proximity to market, transferability (when the

188 technology is mature, but is applied in other industries), retrofittability, scalability, novelty.

189 All techniques were scored on a scale of: -1 (worse than), 0 (similar to), or +1 (better than)

190 contemporary water/wastewater technologies. This scoring range allowed for both subjective

191 and objective analysis to be undertaken depending on the volume of information available.

192 Each criterion was given a weighting of 5, apart from the "novelty" criterion, which was 
193 given a significantly higher weighting (of 20), to ensure that technologies new to the water

194 industry were highlighted. This was a key aim of the study: to bring technologies to the

195 attention of the water industry that would usually be deemed too far from market/the water

196 industry. An UKWIR project steering group representing seven UK water companies

197 provided regular input and feedback.

A total of 393 technology/application combinations were identified and systematically assessed for application in the water industry by comparing and contrasting recent developments, emerging techniques/technologies, and technologies presently employed within the wider industrial sector, as well as examples in the water/wastewater industry both in the UK and globally for water, wastewater and sludge treatment. The full matrix of technologies and applications is available in the supplementary material.

The 9 technologies described in sections 3.1 to 3.9, following, were selected as the most promising novel technologies for the UK water industry.

\subsection{Non-thermal Plasmas (NTPs)}

\subsubsection{NTP Technology}

211

Plasmas are fully or partially ionised gases, often described as "the fourth state of matter".

213 They typically contain various reactive species: photons, ions, ozone, and free radicals

214 (Dobrin et al., 2013; Lukes et al., 2005; Magureanu et al., 2015). These species cause a wide

215 range of chemical reactions to take place at or around ambient temperature. They can be

216 created thermally, but this requires thousands of degrees Celsius. "Non-thermal" plasmas

217 (NTPs), on the other hand, are generated by subjecting gas or liquid streams to high voltage

218 electrical pulses. This opens up a range of applications that would be precluded on grounds of 219 cost, were they to be achieved by thermal means (as operating at high temperature tends to incur substantial capital costs).

\subsubsection{Opportunities}

Most WwTPs are not designed to remove or reduce "micro-pollutants", such as

224 pharmaceuticals (Feng et al., 2013; Gardner et al., 2013; Magureanu et al., 2015). Removal efficiencies below $20 \%$ have been found for compounds including the beta-blockers atenolol, 
226

227

228

229

230

231

232

233

234

235

236

237

238

239

240

241

242

243

244

245

246

247

248

249

250

251

252

253

254

255

256

257

258

259

metoprolol and propranolol, the antibiotics erythromycin, sulfamethoxazole and trimethoprim, the anti-inflammatories diclofenac, indomethacin, ketoprofen and mefenamic acid, the antiepileptic carbamazepine and the antiacid omeprazole (Rosal et al., 2010). However, Dobrin et al (2013) found that the non-steroidal anti-inflammatory drug (NSAID) diclofenac, a "pseudo-persistent pollutant” (Tixier et al., 2003; Zhang et al., 2008), could be completely removed by 15 minutes of NTP treatment. Gerrity et al (2010) (Gerrity et al., 2010)used a pilot-scale pulsed corona discharge plasma to degrade trace organic compounds, including pharmaceuticals and potential EDCs. They found that exactly which compounds were degraded depended upon the power: carbamazepine required relatively little power, whereas more "resistant" compounds such as meprobamate required considerably more. There can therefore be an element of "tuning" to this technology.

NTPs could be a viable alternative to AOPs such as $\mathrm{UV} / \mathrm{H}_{2} \mathrm{O}_{2}$ and ozone/ $/ \mathrm{H}_{2} \mathrm{O}_{2}$. A key advantage in some scenarios is that NTPs do not require additional feed chemicals. This perhaps lends itself to use in remote areas or developing countries where supply of chemicals is difficult, unreliable or undesirable. The reader is referred to Magureanu et al (2015) for a detailed review of NTP use for the degradation of pharmaceutical compounds in water

Decentralised facilities are a common opportunity for PI technologies, as issues such as footprint become more important. Operation at this scale may be a good "first step" for many intensified technologies, as it does not incur the technical/economic risk associated with the substantial scale-up factors of the "full-scale" water industry. Distributed treatment of pharmaceutical-containing effluents could well be viable at the scale of hospitals, care homes etc (Igos et al., 2012). Such facilities are of a scale to have their own water treatment facilities, and will often have significant levels of pharmaceuticals. Lienert et al (2011) found that, in Switzerland, hospitals contributed up to $38 \%$ of the total pharmaceutical load at WwTPs. Careful targeting of such "hot-spot" areas, by installing compact NTP units, could allow significant percentages of high-risk micro-pollutants to be treated at source.

Odour control can be a significant problem in wastewater processing. NTPs can be used to ionise air that can be merged with waste gas flow, or directly with the main flow containing the odour to convert hydrocarbons to carbon dioxide and water (Schlegelmilch et al., 2005). Ruan et al (2005) demonstrated that simulated odours in municipal WwTPs can be treated effectively. They demonstrated that the maximum removal efficiencies achieved for 
$26085 \mathrm{mg} \cdot \mathrm{m}^{-3}$ of ethanethiol and $750 \mathrm{mg} \cdot \mathrm{m}^{-3}$ of tri-methyl amine, at a gas flow rate of 10.0

$261 \mathrm{~m}^{3} \cdot \mathrm{h}^{-1}$, could be as high as $98 \%$ and $91 \%$, respectively.

\subsubsection{Summary: NTPS}

263

264 Current WwT strategies are failing to effectively remove micro-pollutants, such as 265 pharmaceuticals. Non-thermal plasmas (NTPs) offer rapid removal of micro-pollutants. 266 Decentralised NTP units could be installed into "hot-spot" areas such as hospitals to treat 267 micro-pollutants at the source.

\subsection{Oscillatory Baffled Reactors}

\subsubsection{OBR Technology}

Oscillatory baffled reactors (OBRs) generally consist of a cylindrical column or tube

273 containing equally spaced orifice baffles. Within the OBRs either the baffles or the fluid is

274 oscillated to produce vortices (Figure 3), which are generated when fluid flow passes through

275 the baffles. These vortices effectively form many continuously stirred tank reactors in each

276 inter-baffle zone (Abbott et al., 2013; Phan \& Harvey, 2010).

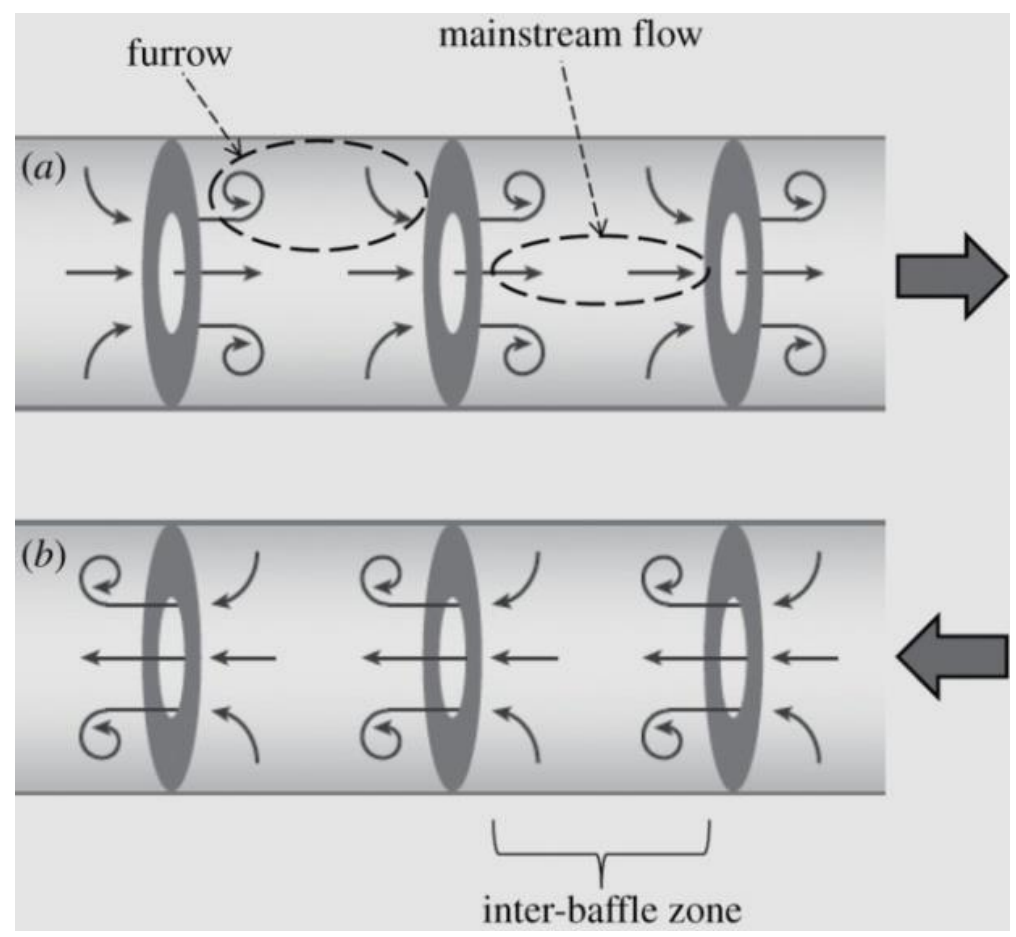


280 Figure 3: Vortex formation in an OBR created by oscillatory flow (a) Back stroke, (b)

281 Forward stroke (Abbott et al., 2013).

282

283

284

285

286

287

288

289

290

291

292

293

294

295

296

297

298

299

300

301

302

303

304

305

306

307

308

309

310

311

\subsubsection{Opportunities}

OBRs could be adapted for many uses within the water and wastewater industry. OBR photoreactors, for example, have been shown to be able to oxidise hydrocarbons in water, by uniformly suspending solid photocatalyst particles $\left(\mathrm{TiO}_{2}\right)$, whilst exposing them to U.V. and dissolved oxygen (Fabiyi \& Skelton, 1999). Enhanced gas-liquid mass transfer in OBRs (Hewgill et al., 1993) may be a particular advantage for applications such as ozonation and chlorination. It has been shown that ozonation is up to three times more efficient in an OBR than in a bubble column (Al-Abduly et al., 2014), which should reduce the size of the ozonation device by the same factor. Similar factors would be expected for other mass transfer-limited applications. Chlorination would be made more effective by the improved uniformity of processing experience in an OBR, which would allow more accurate dosing. Compared to a traditional chlorine contact tank, OBRs would have a significantly smaller footprint due to plug flow, higher mass transfer coefficients and improved mixing. Shorter reaction/contacting times due to the improved mass transfer coefficients would significantly reduce the time of the process, thereby reducing the inventory of hazardous material within the reactor/contactor and the footprint of the contactor $(\mathrm{Ni}, 2006)$.

A further advantage is that OBRs exhibit low shear, efficient global mixing. Research at 5-20L scale into oxidation of pollutants in water (Gao et al., 2003), improving the addition of flocculants, such as aluminium sulphate (Ni et al., 2001).

\subsubsection{Summary: OBRs}

OBRs offer a reduction in footprint, chemical requirements, and processing time for a range of mass transfer-limited applications in the water industry, notably ozonation, hydrocarbon oxidation and chlorination.

\subsection{Ultrasound (US)}

\subsubsection{Ultrasound Technology}


312 Ultrasound (US) refers to sound waves at frequencies above the threshold of human hearing.

313 It can be generated at a broad range of frequencies (20 to $500 \mathrm{kHz}$ ) and acoustic intensities.

314 When US is applied in water the liquid medium will absorb the acoustic energy, creating

315 oscillating regions of positive and negative pressure (Chen et al., 2011), leading to the

316 formation, growth and violent collapse (cavitation) of microbubbles. This releases large

317 amounts of energy, which induces extreme localized conditions: temperatures of up to 5000

$318 \mathrm{~K}$ and pressures up to $500 \mathrm{~atm}$ (Knorr et al., 2013; Wu et al., 2013). US can produce a wide

319 range of physical effects such as microstreaming, microstreamers, microjets, and shock

320 waves (produced by cavitation bubbles) (Chen et al., 2011). Microjets are formed when

321 microbubbles collapse near surfaces, and can be used to clean or scour surfaces.

322

323

324

325

326

327

328

329

330

331

332

333

334

335

336

337

338

339

340

341

342

343

344

\subsubsection{Opportunities}

A number of European countries (Netherlands, Switzerland and Germany) have moved toward potable water delivery systems without residual disinfectants (chlorine, chlorine dioxide, or chloramines). This is partly due to the discovery of disinfection by-products (DBPs), possible human carcinogens in potable water (Rosario-Ortiz et al., 2016). However, use of residual disinfectants is required in the UK due to the estimated average pipe age of 75 to 80 years (DWI, 2010; UKWIR, 2011). Therefore, DBP concentrations are regulated (Rosario-Ortiz et al., 2016). The chemical, mechanical, and biological effects of US can be used for the chemical-free disinfection of water by the direct inactivation of organisms, or by enhancing the effects of other disinfectants (Gibson et al., 2008).

Zou and Wang (2017) recently demonstrated a pilot scale continuous-flow water disinfection system that combined US with chlorine. When a combination of lower frequency US (17 kHz and $33 \mathrm{kHz}$ ) was used as pre-treatment with sodium hypochlorite $(\mathrm{NaClO})$, the required dosage was reduced by two thirds. The action was twofold: disaggregation of bacterial clumps and the weakening of cell walls, allowing easier access for the chlorine. US could also be used for chlorine-free disinfection. Vajnhandl et al (2015) demonstrated a significant increase in E. coli inhibition in 5 minutes, using US alone.

Rosario-Ortiz and Speight (2016) recently recommended that potable water systems should focus on maintaining and replacing their aging delivery systems and consider moving beyond carrying a disinfectant by upgrading their water treatment steps. Ultrasound could be 
345 used as a transitional technique to reduce the required disinfectant in the potable water

346 systems and once adequate pipes are in-place could be implanted as a non-chemical treatment

347 method in combination with established Advanced Oxidation Processes (AOP) (Mahamuni \& 348 Adewuyi, 2010).

In combination with membrane reactors, ultrasound can be used to reduce membrane fouling and increase the efficiency in the purification process. Borea et al (2017) noted that the performance of membrane ultrafiltration was enhanced when at a lower ultrasound frequency of $35 \mathrm{kHz}$ (USMe 35) when compared to $130 \mathrm{kHz}$ due to the stronger vibration and localized turbulence at lower frequency, which act as scrubbers that clean the membrane.

US has also been investigated as a pre-treatment method for sludge treatment processes with a number of reported positive effects, including: improved sludge biodegradability, dewaterability, improving biosolids quality, and shortening the required retention time (Guo et al., 2013; Neumann et al., 2016).

US technology has great promise with a broad range of applications, however the majority of the research remains at the laboratory scale, therefore, the economic feasibility is difficult to predict. Mahamuni and Adewuyi (2010) have calculated that US used in combination with established AOPs was economically more attractive than the use of US alone for WwT. However, the cost of WwT using hybrid ultrasonic processes was estimated to be one to two orders of magnitude more than currently established AOPs. However, commercial standard ultrasonic equipment is developing at great pace within the food industry (Patist \& Bates, 2008), so it is possible that transferable developments may occur, reducing costs and improving efficiencies.

\subsubsection{Summary: US}

370

371 Ultrasound (US) has a wide variety of potential applications within the water and wastewater industry. It can be used in combination with other chemical treatments to increase chlorination efficacy and reduce dosing requirements. However, scale-up of ultrasound is

374 likely to be challenging, but developments within the food industry may provide transferable 375 knowledge 


\subsection{Spinning tube in tube (STT) reactor}

378

379

380

381

382

383

384

385

386

387

388

389

390

391

392

393

394

395

396

397

398

399

400

401

402

403

404

405

406

407

408

\subsubsection{STT Technology}

The spinning tube in tube (STT) reactor consists of two concentric cylindrical surfaces: a rotor and a stationary shell (stator). This creates Couette flow, which mixes the liquids due to the high shear rate. It can be operated continuously or in batch, and could be used for multiple reactions as the changeover of product streams is simple (Jiménez-González \& Constable, 2011).

\subsubsection{Opportunities}

STT reactors have been used in the production of biodiesel by Four Rivers BioEnergy Company, Inc. The STT reactor reportedly reduced reaction time between soybean oil and methanol for biodiesel production to a residence time of $0.5 \mathrm{~s}$ (Qiu et al., 2010). This represents a $>99 \%$ reduction in reaction time, and therefore reactor size. It has also been suggested that it increases selectivity, conversions and yields, and provides real-time control of the quality of chemical processes (Costello, 2006). The STT reactor typically operates at reduced reaction time and mixing power input when compared to conventional reactors, by reducing mixing limitation (Hampton et al., 2008; Qiu et al., 2010). It has been used in: selective oxidation, selective hydrogenation, esterification, transesterification, saponification, hydrosilylation, condensation reactions, and preparation of ionic liquids (Costello, 2006). Note that this selection of applications represents a mixture of liquid-liquid and gas-liquid mixing challenges.

The STT reactor is well suited for the high-volume production of a variety of chemicals and therefore could be utilized in the water/wastewater industry for the enhanced mixing of gas/liquid, liquid/liquid processes, such as chlorination, the addition of flocculants, and potentially the catalysed oxidation of organic pollutants. However, the gap between the rotor and stator could be a significant disadvantage for fluids containing high solids concentrations or larger particles.

STT is an emerging technology and, as yet, has not been applied to the wastewater industry. There is no available data on the operational costs compared to the traditionally used methods. However, it is likely that the STT reactor could reduce residence times, boost reaction rates, minimize side reactions, and reduce energy-intensive downstream processing 
409 steps in mixing-limited processes, such as the applications mentioned above (Costello, 2006).

410 Compared to a traditional chlorine contact tank, STT reactors would have a significantly

411 smaller footprint due to the shorter reaction times engendered by the high shear forces

412 developed within. They are also an example, as are OBRs, of technologies that achieve

413 intensification of processes by facilitating conversion of batch technologies to continuous

414 operation.

415

416 3.4.3 Summary: STTs

417

418

STT reactors are well-suited to high-volume gas/liquid, liquid/liquid processes enhancement.

419 They would reduce footprints, residence time, and downstream process requirements when

420 compared to traditional stirred tanks. However, there has been relatively little research,

421 compared to the other technologies in this study, so for most applications more laboratory-

422 scale investigation would be needed.

423

\subsection{Rotating Packed Beds (RPBs)}

425

426

427

428

429

430

431

432

433

434

435

\subsubsection{RPB Technology}

The RPB creates a high-gravity environment (100 to $500 \mathrm{~g}$ ) via the action of centrifugal force (Wang et al., 2014). A “doughnut" shaped packing material made of foam, mesh, wire, or spheres is used to create a high-specific area (Górak \& Stankiewicz, 2011) (Figure 4). When liquid is passed through the packing of the RPB, it is accelerated and split into fine droplets and thin films, resulting in significant intensification of micro-mixing and mass transfer by one to three orders of magnitude (Górak \& Stankiewicz, 2011; Wang et al., 2014; Yang et al., 2005; Yang et al., 2011). The RPB also has the advantages of smaller equipment size and negligible scale-up effects compared to conventional reactors and, therefore, the volume and weight of the unit is decreased by two or three orders of magnitude (Zhao et al., 2010). 


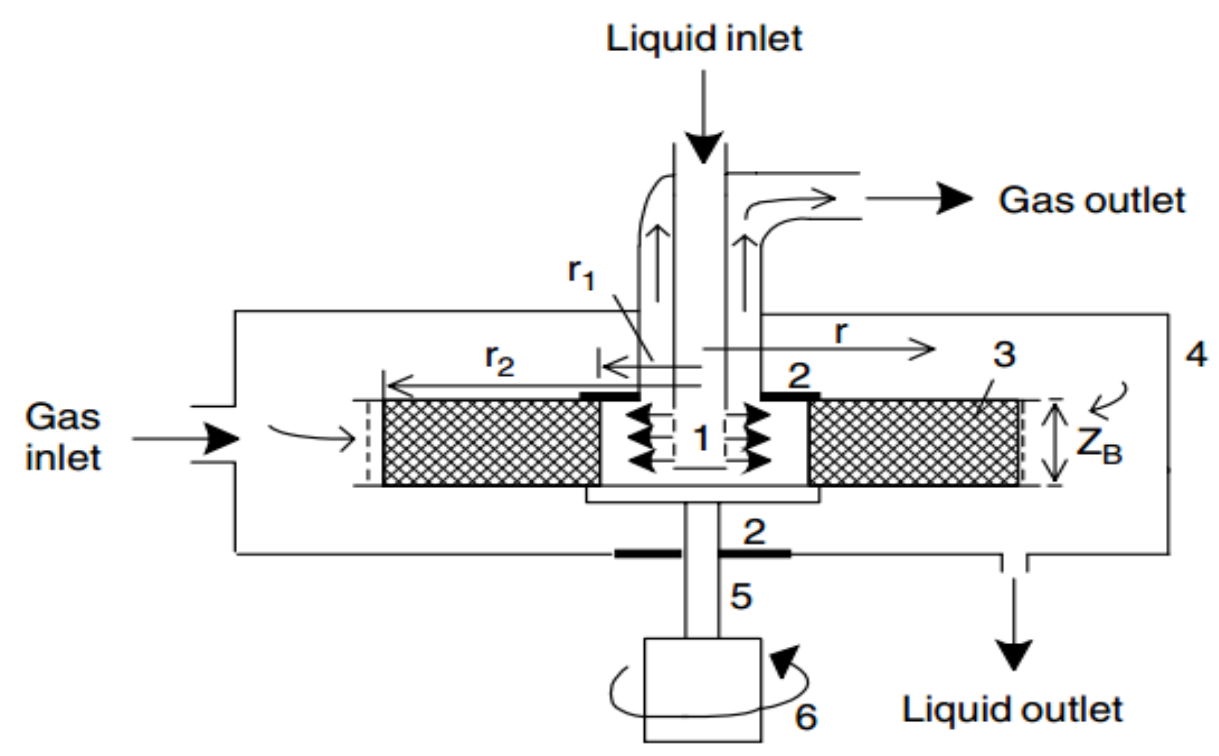

436

437 Figure Error! No text of specified style in document. : A typical RPB gas-liquid Contactor.

438 Components: 1, Stationary liquid distributor; 2, Seal; 3, Packed bed rotator; 4, Housing case; 5, Rotor 439 shaft; 6, Motor (Chen et al., 2005)

440

441

442

443

444

445

446

447

448

449

450

451

452

453

454

455

456

\subsubsection{Opportunities}

RPBs have been successfully employed in industry with processes such as reactive crystallization (Chen \& Shao, 2003; Guo et al., 2000), distillation (Agarwal et al., 2010), seawater deaeration (Rao et al., 2004), and absorption (Lin \& Kuo, 2016).

Yuan et al (2016) recently evaluated a pilot-scale continuous-flow RPB for the removal of ammonia from wastewater. The overall volumetric liquid mass transfer coefficient $\left(K_{\mathrm{L} a}\right)$ and the stripping efficiency $(\eta)$ for ammonia were significantly enhanced, and required very short liquid hydraulic retention times $\left(t_{\mathrm{L}}\right)$ (a few seconds). However, there is the drawback of higher power consumption, due to the energy required to rotate the machinery. It is vital that new research is conducted that considers water/WwTPs holistically, as an increased investment in energy using a RPB could ultimately reduce the overall energy of processing, and reduce the chemical dosing requirements. RPB technology could also remove the majority of the complications related to biological processes used for ammonia from wastewaters such as: sensitivity to shock, toxic loads, and cold weather conditions, relatively longer retention time, and larger spatial requirements (Yuan et al., 2016). 
457

458

459

460

461

462

463

464

465

466

467

468

469

470

471

472

473

474

475

476

477

478

479

480

481

482

483

484

485

486

487

A number of studies have focussed on the combination of RPB and ozone with photolysis and catalysts for the removal of pollutants (Chang et al., 2009; Chen et al., 2005; Chen et al., 2004; Zeng et al., 2012). It was found that total organic carbon mineralization efficiency can be enhanced to $56 \%$ for RPB + UV + ozone, $57 \%$ for RPB + catalysts + ozone, and $45 \%$ for RPB + ozone (Chang et al., 2009).

A significant downside for some applications in the water industry is the narrow interstices through which fluids have to flow in RPBs. These are likely to block and foul, which would severely limit RPB use with fluids containing solids.

The reduction of required volume and footprint means that RPBs could ideally be used in decentralised unit operations, or a number of small units could be used in parallel to remove the need for large contact tanks. RPBs could also be used for odour removal and EP removal, when combined with catalysts.

\subsubsection{Summary: RPBS}

RPBs intensify micro-mixing, and reduce footprint, operational weight, and chemical dosing requirements when compared to conventional technologies. They have potential applications for chlorination, odour removal, and EP removal (when combined with catalysts). The potential drawbacks of RPBs for the WwT industry include higher power consumption and the narrow interstices through which fluid flows (which would not be compatible with particle-laden flows).

\subsection{Ultraviolet light emitting diodes (UV-LEDs)}

\subsubsection{UV-LED Technology}

Ultraviolet light emitting diodes (UV-LEDs) offer a mercury-free source of monochromatic UV radiation. They offer significant advantages when compared to conventional mercury lamps due to their compact form, low power requirements, high efficiency, non-toxicity, and overall robustness (Song et al., 2016; Würtele et al., 2011). UV-LEDs are also capable of emitting light in a narrow wavelength range in the form of electroluminescence (Taniyasu et al., 2006), unlike the currently used low- or medium-pressure mercury lamps that have a wide 
488

489

490

491

492

493

494

495

496

497

498

499

500

501

502

503

504

505

506

507

508

509

510

511

512

513

514

515

516

517

518

519

spectral power distribution (Peters, 2012). Studies using UV-LEDs have shown that the most effective wavelength for disinfection is $275 \mathrm{~nm}$ (Bowker et al., 2011; Peters, 2012). UVLEDs have been shown to deactivate a the diversity of different microorganisms at various wavelengths such as; E.coli, staphylococcus, Salmonella, and Bacillus subtilis (Song et al., 2016).

\subsubsection{Opportunities}

Applications for UV-LEDs include water disinfection (Bak et al., 2010; Song et al., 2016; Würtele et al., 2011) and the degradation of organic compounds and micropollutants (Autin et al., 2013; Jamali et al., 2013; Natarajan et al., 2011). Currently the low output power and current high investment costs are the major limitations to the application of UV-LEDs (Autin et al., 2013; Bak et al., 2010; Würtele et al., 2011). However, LEDs are developing quickly and are projected to overcome these limitations by 2020 (Autin et al., 2013). For example the cost of LEDs has reduced by a factor of 7 within the last 5 years (Autin et al., 2013).

Improvements in performance indicators may make UV-LEDs economically competitive in under ten years (Autin et al., 2013; Crook et al., 2015; Ibrahim et al., 2014; Umar et al., 2015). In the near future UV-LEDs have the potential to be combined with microwave technology for water disinfection potentially reducing the footprint, required operational, labour, and maintenance costs, operational safety, and lower cost of labour and maintenance when compared to conventional UV treatment (See section 3.7 Microwave Processing)

A further significant advantage of UV-LEDs is that they have a significantly higher functioning lifetime (50,000-100,000 h) than mercury lamps (2,000-10,000 h) (Song et al., 2016). Hence, LEDs could easily be integrated into current systems, gradually replacing mercury lamps, as they come to the end of their lifetimes, i.e. their "retrofittability" is an advantage. Given UV-LEDs compact design and radiation patterns, they will enable greater creative reactor designs for future applications, through the optimization of flow and radiation distribution, as well as reactor geometry and kinetics (Song et al., 2016).

Their small size offers considerable flexibility in their potential areas of application. Point of use sterilisation could be an effective way to remove the need for residual disinfectants and the formation of DBPs, thus improving water safety. However, the design 
520 and implementation of the unit could be difficult. The ideal point of use UV-LED sterilisation unit would be retro-fitted into domestic taps.

\subsubsection{Summary: $U V-L E D s$}

523

LEDS are transforming domestic and industrial lighting as they are compact, robust, non-toxic, highly efficient and have low power requirements. These advantages should also be exploited for UV-LEDs in the water and chemicals industry. They are retrofittable, and should be able to replace mercury lamps, as they come to the end of their lifetime. Generally, this suggests applications in water disinfection, degradation of organic compounds and micropollutants, ensuring water at discharge meets present legislations and the potentially stricter future legislations. However, UV-LEDs can, in principle, be used for applications where the use of traditional mercury lamps is impractical or impossible, or wholly new uses. These include:

\subsection{Microwave Processing}

534

535

\subsubsection{Microwave Technology}

Microwaves are commonly used for drying in the food industry (Ramaswamy \& Tang, 2008). Their advantage is often their "volumetric" heating of water, rather than the outside-in heating of conventional convective heat transfer. This often leads to more rapid drying or heating of water-filled solids.

Microwave dryers have been shown to substantially reduce drying times, thereby reducing dryer size. One example from the food industry is illustrative: a microwave dryer was used to reduce the drying time of pasta from 10-20 hours to 15 minutes, thereby allowing for significant increases in production rates (Reay et al., 2013).

\subsubsection{Opportunities}

Microwaves can also be used in combination with other techniques such as oxidants, catalysts, and advanced oxidation techniques (Remya \& Lin, 2011). Microwaves have also been investigated for use as pre-treatments for temperature-phased anaerobic digestion, Coelho et al (2011) reported maximum volatile solids (VS) removal of up to $53.1 \%$ at a sludge retention time of 15 days, and maximum biogas increase relative to control was $106 \%$ after 5 days sludge retention time. When microwaves are combined with oxidants, free 
552 radical generation occurs and the pollutant molecule is rapidly polarized (Zhang et al., 2007).

553 High reaction rates can be achieved compared to traditional thermal or catalytic oxidation.

554 This is due to localised heating of solids, particularly metal-containing catalyst particles. The 555 temperature increase can be hundreds of degrees. Jou et al (2008) combined microwaves at

$556700 \mathrm{~W}$ for 30 seconds, with $\mathrm{Fe}^{0}$ acting as a catalyst to remove the pollutant

557 pentachlorophenol (PCP), from contaminated wastewater. A removal of $>99 \%$ was achieved.

Microwave radiation has been applied at bench-scale for the removal of ammonia from wastewater, achieving 100\% removal in $3 \mathrm{~min}$ (Lin et al., 2009b). The same technique was then applied at a pilot scale $\left(28 \mathrm{~L}^{-1}\right)$. A removal efficiency of $80 \%$ was achieved in a treatment time of $80 \mathrm{~min}$ (Lin et al., 2009a).

563

An exciting development in the disinfection of wastewater, drinking water, and for water reuse application is the coupling of UV disinfection with microwave energy to power the electrodes. The microwave energy is generated by a magnetron, as in domestic microwave ovens, and directed through a waveguide into high-output electrode free quartz lamps. Severn Trent Services has launched the MicroDynamics Series OCS721, which is a microwave-UV system. Four modules have been running at a Leacock (USA) plant since 2010. The four modules are able treat 2.4 million gallons/day. The disinfection system has a total cycle time of 41 minutes, and as the lamps are electrode-free it allows the system to have unlimited starts and stops, which allows for the system to adapt to the flow rate. The system has many advantages over conventional UV treatments: greater operating cost savings; lower whole-life cost; and increased lamp life in a smaller footprint (Shima, 2011).

\subsubsection{Summary: Microwave Processing}

Microwaves offer a diverse range of applications within the water industry, including: drying, temperature-phased anaerobic digestion, ammonia removal, degradation of pollutants, and disinfection.

A particular technology of interest is the coupling of UV disinfection with microwave energy to power the electrodes. This offers operating cost savings, lower whole-life costs, long lamp life, a smaller footprint, and lower cost of labour and maintenance when compared to 
584 conventional UV treatment. UV disinfection with microwave is a mature technology and could be implemented near term.

586

\subsubsection{DOF Technology}

590

591 Dissolved ozone flotation combines a conventional dissolved air flotation (DAF) system with ozone. Using ozone in a DAF unit instead of atmospheric air induces the production of nano/micro-ozone bubbles, where the ozone is supplied through a simple porous diffuser at the bottom of the reactor (Lee et al., 2008). The use of Dissolved Ozone Flotation (DOF) integrates two processes into one unit: (i) the separation of solids and emulsions by gas bubbles (as in conventional flotation) and (ii) oxidation of soluble organic compounds (Wilinski \& Naumczyk, 2012), hence the process intensification.

\subsubsection{Opportunities}

600

601 Lee et al (2008) compared a conventional mechanical diffuser used for ozone contact with DOF, and showed that the DOF significantly outperformed the conventional diffuser in terms of turbidity, TSS, colour, COD, BOD, nitrogen, phosphorus and aerobic bacteria. DOF can: decrease the dosing requirements of coagulants and flocculants, increase pathogen removal, improve wastewater biodegradability, remove micro-pollutants (antibiotics, hormones, personal care products), and reduce the amount of excess biological sludge (when DOF is used for separation of effluent from excess activated sludge) (Jin et al., 2006; Jin et al., 2015;

608 Lee et al., 2007; Wilinski \& Naumczyk, 2012). Furthermore, the off-gas of the DOF system 609 may be used to remove or reduce odour emissions (Jin et al., 2006; Kim et al., 2011; Wilinski $610 \&$ Naumczyk, 2012).

613 DOF and estimated the cost reductions of DOF for the biological step of WwT. Taking into 614 consideration the additional costs associated with ozone generation Wilinski and Naumczyk 615 (2012) calculated the total savings incurred by using DOF rather than DAF to be $€ 32,000$ 
616 per annum. This was due to the reduction in iron (III) sulphate requirement, lower sludge

617 production, and the lower energy consumption by air blower. Lee et al (2008) compared DOF

618 with other relevant technologies for municipal WwT, including the costs of chemicals, ozone

619 generation, and power consumption for DOF processing (Table 2):

620

621 Table 2: A comparison of the treatment costs of DOF and other technologies for municipal 622 wastewater treatment (adapted from Lee et al (2008))

\begin{tabular}{|c|c|c|}
\hline Process & $\begin{array}{l}\text { Cost of treatment } \\
\qquad\left(\mathrm{US} \$ / \mathbf{~ m}^{\mathbf{3}}\right)\end{array}$ & Source \\
\hline Dissolved ozone flotation & 0.031 & (Lee et al., 2008) \\
\hline Granular media filtration and chlorination & 0.5 & (Hamoda et al., 2004) \\
\hline Ozone-enhanced electro-flocculation & 0.51 & (Nielson \& Smith, 2005) \\
\hline $\begin{array}{l}\text { Moving bed sand filter, a granular activated } \\
\text { carbon adsorption bed and ozone disinfection }\end{array}$ & 0.31 & (Petala et al., 2006) \\
\hline Dual-membrane & 0.21 & (del Pino \& Durham, 1999) \\
\hline
\end{tabular}

624 However, Jin et al (2015) tested a pilot-scale DOF system and noted the optimal 625 ozone dosage for the DOF process was considerably lower $(x \sim 3)$, so the economic benefit of 626 DOF could be far greater.

\subsubsection{Summary: DOF}

628

629 DOF induces the production of nano/micro-ozone bubbles, which have a very large surface 630 area, thereby greatly enhancing the mass transfer rate. This can decrease the dosing 631 requirements of coagulants and flocculants, offering considerable economic benefits when 632 compared to DAF. The limited amount of literature available suggests that the integration of 633 ozone into conventional DAFs could have considerable impact on a number of areas of water 634 treatment.

635

637 removal, removal of micro-pollutants, and the reduction of odour emissions, compared to 
638 DAF. However, it should be noted that DAF is not widely used in water treatment and so 639 retrofitting, even if the claimed benefits are realised, would be rather limited. The greatest 640 potential for this technology lies in water treatment plants that have a DAF unit, or several 641 DAF units in operation being converted to DOF at very little cost.

642

\subsection{Fluidic Oscillation Devices}

644

645

646

647

648

649

650

651

652

653

654

655

656

657

658

659

660

661

662

663

664

665

666

667

668

669

670

\subsubsection{Technology Description}

Fluidic oscillators convert constant gas flows into oscillatory flows, by creating an instability based on the Coandă effect. Zimmerman et al have developed this technique for the generation of uniform microbubbles (Al-Mashhadani et al., 2012; Hanotu et al., 2013a; Hanotu et al., 2013b; Rehman et al., 2015; Tesař et al., 2006; Zimmerman et al., 2009; Zimmerman et al., 2011; Zimmerman et al., 2008). When an oscillating flow is applied, it creates a "pulse" that provides a lifting force enabling the bubble to break free when significantly smaller (Hanotu et al., 2012; Hanotu et al., 2013b) (Figure 5). Furthermore, the bubbles are released at more similar times, and are similar in size, hence the forces on them are balanced and they rise vertically, meaning that they are less likely to coalesce

\subsubsection{Opportunities}

The increased surface area to volume ratio available in MBs can significantly increase gasliquid mass transfer rates (Hanotu et al., 2013a; Temesgen et al., 2017). These characteristics of MBs and NBs have attracted attention in a variety of fields including water and WwT, water purification, fish farming, shellfish culture, and harvesting of microalgae (Coward et al., 2015; Hanotu et al., 2013b; He et al., 2012; Kaushik \& Chel, 2014; Khuntia et al., 2012; Rehman et al., 2015).

Aeration is one of the most energy intensive processes in WwT, consuming 45-75\% of the total plant energy cost (Rosso et al., 2008). Conventional methods of bubble generation use pore diffusers with a steady flow to produce fine bubbles of 1-3 $\mathrm{mm}$ (Rehman et al., 2015). These techniques are unable to produce MBs due to the buoyancy force required for the bubble to break free from the diffuser and inter-bubble forces causing bubble coalescence (Rehman et al., 2015; Zimmerman et al., 2008). 
671

672

673

674

675

676

677

678

679

680

681

682

683

684

685

686

687

688

689

690

691

692

693
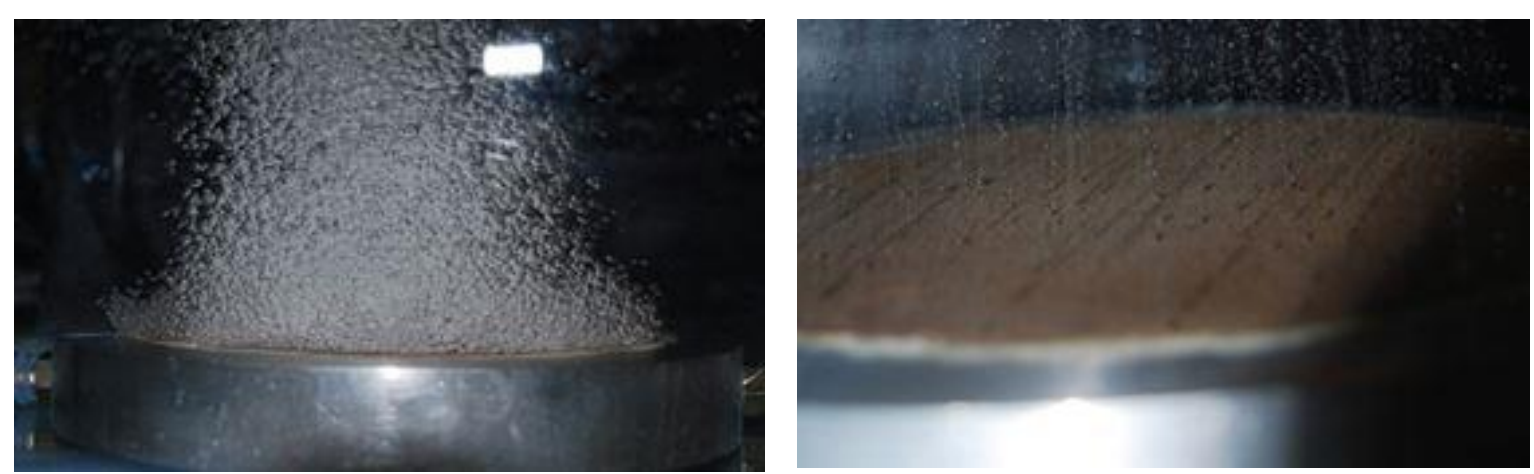

Figure 5: Bubbles created from microporous membrane diffuser, without fluidic oscillation (left). Created from microporous membrane diffuser, with fluidic oscillation (right). (Picture: University of Sheffield)

Aeration is commonly used in activated sludge processes to promote microbial growth. Rehman et al (2015) noted that fluidic oscillator-mediated MB generation could provide cost-effective enhancement of mass transfer and mixing efficiency, increasing the bacteria concentration.

A number of methods for the generation of miniaturised bubbles have been developed, such as; dissolved air flotation (DAF), ultrasound techniques (see section 3.3 Ultrasound) and induced air flotation (IAF). DAF is the most commonly employed technique for the production of MBs, however supersaturating the water is a highly energy intensive process, with more than $90 \%$ of the total operational energy used in DAF being spent on pumping and pressurizing recycled clarified water into the saturator (Hanotu et al., 2013a). It has been suggested that the use of fluidic oscillators could eliminate recycle flow and saturator load required by conventional DAF technologies. Fluidic oscillators could also be combined with ozone to create ozone-rich MBs that could be used to sanitise water (LozanoParada \& Zimmerman, 2010; Temesgen et al., 2017). Khuntia et al (2015) noted that that ozone MBs improved the oxidation of different pollutants by improving the formation of hydroxyl radical for advanced oxidation under acidic and alkaline conditions. Wang et al (2017b) found that the reaction rate when using ozone MBs was three times higher than that in normal ozone when used as an advanced treatment method of concentrated leachate.

696 Fluidic oscillation devices produce micro or nano scale bubbles by converting constant air

697 flows into oscillating air flow without moving parts, and without the need for energy 
698 intensive water supersaturation (DAF). This offers three significant improvements to the

699 WwT process: 1) improved mass transfer rate, 2) reduced energy usage and 3) improved

700 mixing, could bring significant benefits to industry.

$701 \mathrm{MB}$ aeration technology can be retrofitted to existing plants, potentially with little disruption,

702 and can therefore be implemented in the near-term for a number of water and WwT

703 applications. An intriguing possibility is to use the generators with ozone to create ozone-rich 704 microbubbles for water sanitisation.

The UK water industry is facing a variety of challenges such as; meeting future legislation on water quality, increasing population densities, and water demand, new and emerging pollutants, and reducing energy use. However, the potential to address these challenges is extremely limited, if not amplified, due to the UK's aging water infrastructure, the industry's risk-averse attitudes, and a lack of knowledge and understanding about new and emerging technologies.

Process intensification (PI) is a chemical and process design approach that leads to substantially smaller, cleaner, safer and more energy-efficient process technology. This review identified 9 new and emerging novel PI technologies that could be applied to the UK water industry to gain a step-change in processing potential. The majority the PI technologies also offer the opportunity for either: 1) small foot-print, decentralised facilities that could be located at "hot-spots", reducing the complexity of waters entering the traditional centralised system, or 2) technologies that could be retrofitted into the current facilities, improving processing potential or reducing energy requirements.

However, this is by no means a comprehensive review of all possible novel intensified technologies that can be used in the UK water industry. The field of intensified process technology is vast, and the set of possible process steps in water processing is substantial. The full matrix (available in supplementary material) demonstrates the extensive range of PI technologies and processes assessed. Technologies that scored relatively highly but were not included in this review include: aerobic granular sludge, membrane-aerated biofilm reactors, magnetite ballasted activated sludge, electro-dewatering, and anti-scale/ FOG technology. that can occur when PI technologies are adopted, such as: more efficient, safer, flexible, 
731

732

733

734

735

736

737

738

739

740

741

742

743

744

745

746

747

748

749

750

751

752

753

754

755

756

757

758

759

760

smaller, cheaper and more environmentally friendly processes. It has also been demonstrated that drastic changes can occur when a water sector embraces innovation and invests in research, such as the Singaporean water industry. Therefore, to ensure the continued adoption of PI techniques into the water industry the following three measures are recommended:

1. Distributed Water Treatment: A review of PI or other technologies specifically for future distributed water treatment systems may be timely. This should be an area where intensified technologies can make a significant difference to the economics and capabilities of water treatment, with more certainty about the process technology performance at full scale. The greatest technical risk for many of the technologies reported here is scale-up, and the risk increases with the scale-up factor. Furthermore, some technologies are inherently difficult to envisage at the largest scales in the water industry.

2. Mass Transfer Enhancement: There are a variety of novel technologies, notably rotating packed beds, but also oscillatory baffled reactors, fluidic oscillators, and spinning tube-in-tube reactors that could be used to enhance gas-liquid mass transfer to intensify process steps such as chlorination or ozonation and oxygen transfer. A more detailed comparative design study and/or techno-economic study is required to determine which technologies would be most economically viable in practice.

3. Knowledge exchange: A number of technologies have commercial examples, but are not yet used in large numbers, or could be used at large scale in the near term. There is therefore the need for knowledge exchange by current users for the common good. Knowledge exchange programs or fact-finding missions are recommended.

\section{Acknowledgments}

This work was funded by UKWIR (Grant No. RG10), leading to UKWIR report 15/RG/10/8. The authors would like to thank the members of the UKWIR Project Steering Group: Dr Manocher Asaadi (UKWIR), Cathy Gillett, Andrew Moore, Kylie Symes, Chris Royce, Mark Jones, and Peter Pearce for their valuable feedback during this work. 
762 TC, HT and AH designed the methodologies for collecting data on the PI technique; TC and

763 AH analyzed the data; HT contributed materials. TC and AH wrote this manuscript.

\section{Conflicts of Interest}

765 The authors declare no conflict of interest

766

767

768

769

770

771

772

773

774

775

776

777

778

779

780

781

782

783

784

785

786

787

788

789

790

791

\section{References}

Abbott, M.S.R., Harvey, A.P., Perez, G.V., Theodorou, M.K. 2013. Biological processing in oscillatory baffled reactors: operation, advantages and potential. Interface Focus, 3(1).

Acerini, C.L., Hughes, I.A. 2006. Endocrine disrupting chemicals: a new and emerging public health problem? Archives of Disease in Childhood, 91(8), 633-641.

Adeel, M., Song, X., Wang, Y., Francis, D., Yang, Y. 2017. Environmental impact of estrogens on human, animal and plant life: A critical review. Environment International, 99(Supplement C), 107-119.

Agarwal, L., Pavani, V., Rao, D.P., Kaistha, N. 2010. Process intensification in HiGee absorption and distillation: Design procedure and applications. Industrial \& engineering chemistry research, 49(20), 10046-10058.

Al-Abduly, A., Christensen, P., Harvey, A., Zahng, K. 2014. Characterization and optimization of an oscillatory baffled reactor (OBR) for ozone-water mass transfer. Chemical Engineering and Processing: Process Intensification, 84(Supplement C), 82-89.

Al-Mashhadani, M.K.H., Bandulasena, H.C.H., Zimmerman, W.B. 2012. $\mathrm{CO}_{2}$ mass transfer induced through an airlift loop by a microbubble cloud generated by fluidic oscillation. Industrial \& engineering chemistry research, 51(4), 1864-1877.

Autin, O., Romelot, C., Rust, L., Hart, J., Jarvis, P., MacAdam, J., Parsons, S.A., Jefferson, B. 2013. Evaluation of a UV-light emitting diodes unit for the removal of micropollutants in water for low energy advanced oxidation processes. Chemosphere, 92(6), 745-751.

Bak, J., Ladefoged, S.D., Tvede, M., Begovic, T., Gregersen, A. 2010. Disinfection of Pseudomonas aeruginosa biofilm contaminated tube lumens with ultraviolet $\mathrm{C}$ light emitting diodes. Biofouling, 26(1), 31-38. 
792

793

794

795

796

797

798

799

800

801

802

803

804

805

806

807

808

809

810

811

812

813

814

815

816

817

818

819

820

821

822

823

824

825

Borea, L., Naddeo, V., Shalaby, M.S., Zarra, T., Belgiorno, V., Abdalla, H., Shaban, A.M. 2017. Wastewater treatment by membrane ultrafiltration enhanced with ultrasound: Effect of membrane flux and ultrasonic frequency. Ultrasonics.

Bowker, C., Sain, A., Shatalov, M., Ducoste, J. 2011. Microbial UV fluence-response assessment using a novel UV-LED collimated beam system. Water Research, 45(5), 2011-2019.

Buchholz, S. 2010. Future manufacturing approaches in the chemical and pharmaceutical industry. Chemical Engineering and Processing: Process Intensification, 49(10), 993995.

Chang, C.-C., Chiu, C.-Y., Chang, C.-Y., Chang, C.-F., Chen, Y.-H., Ji, D.-R., Yu, Y.-H., Chiang, P.-C. 2009. Combined photolysis and catalytic ozonation of dimethyl phthalate in a high-gravity rotating packed bed. Journal of hazardous materials, 161(1), 287-293.

Charpentier, J.-C. 2007. Modern chemical engineering in the framework of globalization, sustainability, and Technical Innovation. Industrial \& engineering chemistry research, 46(11), 3465-3485.

Chen, D., Sharma, S.K., Mudhoo, A. 2011. Handbook on Applications of Ultrasound: Sonochemistry for Sustainability. CRC Press

Chen, J., Shao, L. 2003. Mass production of nanoparticles by high gravity reactive precipitation technology with low cost. China Particuology, 1(2), 64-69.

Chen, Y.-H., Chang, C.-Y., Su, W.-L., Chiu, C.-Y., Yu, Y.-H., Chiang, P.-C., Chang, C.-F., Shie, J.-L., Chiou, C.-S., Chiang, S.I.M. 2005. Ozonation of CI reactive black 5 using rotating packed bed and stirred tank reactor. Journal of Chemical Technology \& Biotechnology, 80(1), 68-75.

Chen, Y., Chang, C., Su, W., Chen, C., Chiu, C., Yu, Y., Chiang, P., Chiang, S.I. 2004. Modeling ozone contacting process in a rotating packed bed. Industrial \& engineering chemistry research, $43(1), 228-236$.

Coelho, N.M.G., Droste, R.L., Kennedy, K.J. 2011. Evaluation of continuous mesophilic, thermophilic and temperature phased anaerobic digestion of microwaved activated sludge. Water Research, 45(9), 2822-2834.

Costello, R. 2006. Tiny reactors aim for big role. in: Chemical Processing.

Coward, T., Lee, J.G.M., Caldwell, G.S. 2015. The effect of bubble size on the efficiency and economics of harvesting microalgae by foam flotation. Journal of Applied Phycology, 27(2), 733-742. 
826 Crook, M.J., Jefferson, B., Autin, O., MacAdam, J., Nocker, A. 2015. Comparison of

827

828

829

830

831

832

833

834

835

836

837

838

839

840

841

842

843

844

845

846

847

848

849

850

851

852

853

854

855

856

857

858

859 ultraviolet light emitting diodes with traditional UV for greywater disinfection. Journal of Water Reuse and Desalination 5, 17-27.

CST. 2009. Improving innovation in the water industry: 21 st century challenges and opportunities. Council for Science and Technology.

Dautzenberg, F.M., Mukherjee, M. 2001. Process intensification using multifunctional reactors. Chemical Engineering Science, 56(2), 251-267.

Defra. 2010. National policy statement for wastewater: A framework document for planning decisions on nationally significant wastewater infrastructure, Department for Environment, Food \& Rural Affairs. London.

del Pino, M.P., Durham, B. 1999. Wastewater reuse through dual-membrane processes: opportunities for sustainable water resources. Desalination, 124(1), 271-277.

Dobrin, D., Bradu, C., Magureanu, M., Mandache, N.B., Parvulescu, V.I. 2013. Degradation of diclofenac in water using a pulsed corona discharge. Chemical Engineering Journal, 234(Supplement C), 389-396.

European Communities, 2000. Directive 2000/60/EC of the European Parliament and of the Council of 23 October 2000 establishing a framework for community action in the field of water policy. Official journal of the European Communities L327(43), 1-72

European Commission, 2008. Priority substances daughter directive-directive 2008/105/EC of the European Parliament and of the council of 16 December 2008 on environmental quality standards in the field of water policy. Official Journal of the European Community 348, 84-97.

DWI. 2010. The Water Supply Regulations, Statutory Instrument 2010 No. 991.

Fabiyi, M.E., Skelton, R.L. 1999. The application of oscillatory flow mixing to photocatalytic wet oxidation. Journal of Photochemistry and Photobiology A: Chemistry, 129(1), 1724.

Feng, X., Patterson, D.A., Balaban, M., Fauconnier, G., Emanuelsson, E.A.C. 2013. The spinning cloth disc reactor for immobilized enzymes: A new process intensification technology for enzymatic reactions. Chemical Engineering Journal, 221, 407-417.

Gao, P., Han Ching, W., Herrmann, M., Kwong Chan, C., Yue, P.L. 2003. Photooxidation of a model pollutant in an oscillatory flow reactor with baffles. Chemical Engineering Science, 58(3), 1013-1020.

Gardner, M., Jones, V., Comber, S., Scrimshaw, M.D., Coello - Garcia, T., Cartmell, E., Lester, J., Ellor, B. 2013. Performance of UK wastewater treatment works with 
860

861

862

863

864

865

866

867

868

869

870

871

872

873

874

875

876

877

878

879

880

881

882

883

884

885

886

887

888

889

890

891

892

respect to trace contaminants. Science of The Total Environment, 456(Supplement C), 359-369.

Gavrilescu, M., Demnerová, K., Aamand, J., Agathos, S., Fava, F. 2015. Emerging pollutants in the environment: present and future challenges in biomonitoring, ecological risks and bioremediation. New Biotechnology, 32(1), 147-156.

Geissen, V., Mol, H., Klumpp, E., Umlauf, G., Nadal, M., van der Ploeg, M., van de Zee, S.E.A.T.M., Ritsema, C.J. 2015. Emerging pollutants in the environment: A challenge for water resource management. International Soil and Water Conservation Research, 3(1), 57-65.

Georges, K., Thornton, A., Sadler, R. 2009. Transforming wastewater treatment to reduce carbon emissions, The Environment Agency. Bristol.

Gerrity, D., Stanford, B.D., Trenholm, R.A., Snyder, S.A. 2010. An evaluation of a pilotscale nonthermal plasma advanced oxidation process for trace organic compound degradation. Water Research, 44(2), 493-504.

Gibson, J.H., Yong, D.H.N., Farnood, R.R., Seto, P. 2008. A literature review of ultrasound technology and its application in wastewater disinfection. Water quality research journal of Canada, 43(1), 23-35.

Górak, A., Stankiewicz, A. 2011. Intensified reaction and separation systems. Annual Review of Chemical and Biomolecular Engineering, 2(1), 431-451.

Guo, K., Guo, F., Feng, Y., Chen, J., Zheng, C., Gardner, N.C. 2000. Synchronous visual and RTD study on liquid flow in rotating packed-bed contactor. Chemical Engineering Science, 55(9), 1699-1706.

Guo, W.-Q., Yang, S.-S., Xiang, W.-S., Wang, X.-J., Ren, N.-Q. 2013. Minimization of excess sludge production by in-situ activated sludge treatment processes - A comprehensive review. Biotechnology advances, 31(8), 1386-1396.

Hamoda, M.F., Al-Ghusain, I., Al-Mutairi, N.Z. 2004. Sand filtration of wastewater for tertiary treatment and water reuse. Desalination, 164(3), 203-211.

Hampton, P.D., Whealon, M.D., Roberts, L.M., Yaeger, A.A., Boydson, R. 2008. Continuous organic synthesis in a spinning tube-in-tube reactor: TEMPO-catalyzed oxidation of alcohols by hypochlorite. Organic Process Research \& Development, 12(5), 946-949.

Hanotu, J., Bandulasena, H.C.H., Chiu, T.Y., Zimmerman, W.B. 2013a. Oil emulsion separation with fluidic oscillator generated microbubbles. International Journal of Multiphase Flow, 56(Supplement C), 119-125. 
893 Hanotu, J., Bandulasena, H.C.H., Zimmerman, W.B. 2012. Microflotation performance for

894

895

896

897

898

899

900

901

902

903

904

905

906

907

908

909

910

911

912

913

914

915

916

917

918

919

920

921

922

923

924

925 algal separation. Biotechnology and Bioengineering, 109(7), 1663-1673.

Hanotu, J., Ying, K., Shada, O.I., Bandulasena, H., Zimmerman, W.B. 2013b. Microalgae recovery by microflotation for biofuel production using metallic coagulants. Biofuels, 4(4), 363-369.

Harmsen, J. 2010. Process intensification in the petrochemicals industry: Drivers and hurdles for commercial implementation. Chemical Engineering and Processing: Process Intensification, 49(1), 70-73.

He, W., Li, Z., Fan, Y., Liang, Y., Scales, P. 2012. The development and applications of microbubble generators especially for wastewater treatment. Advanced Materials Research, 518-523, 2891-2894.

Hewgill, M.R., Mackley, M.R., Pandit, A.B., Pannu, S.S. 1993. Enhancement of gas-liquid mass transfer using oscillatory flow in a baffled tube. Chemical Engineering Science, 48(4), 799-809.

Ibrahim, M.A.S., MacAdam, J., Autin, O., Jefferson, B. 2014. Evaluating the impact of LED bulb development on the economic viability of ultraviolet technology for disinfection. Environmental Technology, 35(4), 400-406.

Igos, E., Benetto, E., Venditti, S., Kohler, C., Cornelissen, A., Moeller, R., Biwer, A. 2012. Is it better to remove pharmaceuticals in decentralized or conventional wastewater treatment plants? A life cycle assessment comparison. Science of The Total Environment, 438(Supplement C), 533-540.

Jamali, A., Vanraes, R., Hanselaer, P., Van Gerven, T. 2013. A batch LED reactor for the photocatalytic degradation of phenol. Chemical Engineering and Processing: Process Intensification, 71(Supplement C), 43-50.

Jiménez-González, C., Constable, D.J.C. 2011. Pocess Intensification. in: Green Chemistry and Engineering: A Practical Design Approach, John Wiley \& Sons, pp. 430-431.

Jin, P.K., Wang, X.C., Hu, G. 2006. A dispersed-ozone flotation (DOF) separator for tertiary wastewater treatment. Water Science and Technology, 53(9), 151-157.

Jin, X., Jin, P., Wang, X. 2015. A study on the effects of ozone dosage on dissolved-ozone flotation (DOF) process performance. Water Science and Technology, 71(9), 14231428.

Jou, C.-J. 2008. Degradation of pentachlorophenol with zero-valence iron coupled with microwave energy. Journal of hazardous materials, 152(2), 699-702. 
926 Kaushik, G., Chel, A. 2014. Microbubble technology: emerging field for water treatment. Bubble Science, Engineering \& Technology, 5(1-2), 33-38.

928

929

930

931

932

933

934

935

936

937

938

939

940

941

942

943

944

945

946

947

948

949

950

951

952

953

954

955

956

957

958

Khuntia, S., Majumder, S.K., Ghosh, P. 2015. Quantitative prediction of generation of hydroxyl radicals from ozone microbubbles. Chemical Engineering Research and Design, 98(Supplement C), 231-239.

Khuntia, S., Majumder Subrata, K., Ghosh, P. 2012. Microbubble-aided water and wastewater purification: a review, Reviews in Chemical Engineering, 28,191-221.

Kim, J.H., Kim, H.S., Lee, B.H. 2011. Combination of sequential batch reactor (SBR) and dissolved ozone flotation-pressurized ozone oxidation (DOF-PO2) processes for treatment of pigment processing wastewater. Environmental Engineering Research 16(2), 97-102.

Knorr, D., Froehling, A., Jaeger, H., Reineke, K., Schlueter, O., Schoessler, K. 2013. Emerging Technologies for Targeted Food Processing. in: Advances in Food Process Engineering Research and Applications, (Eds.) S. Yanniotis, P. Taoukis, N.G. Stoforos, V.T. Karathanos, Springer US. Boston, MA, pp. 341-374.

Lee, B.-H., Song, W.-C., Kim, H.-Y., Kim, J.-H. 2007. Enhanced separation of water quality parameters in the DAF (Dissolved Air Flotation) system using ozone. Water Science and Technology, 56(10), 149-155.

Lee, B.H., Song, W.C., Manna, B., Ha, J.K. 2008. Dissolved ozone flotation (DOF) - a promising technology in municipal wastewater treatment. Desalination, 225(1), 260273.

Lienert, J., Koller, M., Konrad, J., McArdell, C.S., Schuwirth, N. 2011. Multiple-criteria decision analysis reveals high stakeholder preference to remove pharmaceuticals from hospital wastewater. Environmental Science \& Technology, 45(9), 3848-3857.

Lin, C.-C., Kuo, Y.-W. 2016. Mass transfer performance of rotating packed beds with blade packings in absorption of $\mathrm{CO}_{2}$ into MEA solution. International Journal of Heat and Mass Transfer, 97(Supplement C), 712-718.

Lin, L., Chen, J., Xu, Z., Yuan, S., Cao, M., Liu, H., Lu, X. 2009a. Removal of ammonia nitrogen in wastewater by microwave radiation: A pilot-scale study. Journal of hazardous materials, 168(2), 862-867.

Lin, L., Yuan, S., Chen, J., Xu, Z., Lu, X. 2009b. Removal of ammonia nitrogen in wastewater by microwave radiation. Journal of hazardous materials, 161(2), 1063 1068. 
959 Lozano-Parada, J.H., Zimmerman, W.B. 2010. The role of kinetics in the design of plasma

960 microreactors. Chemical Engineering Science, 65(17), 4925-4930.

961 Lukes, P., Clupek, M., Babicky, V., Janda, V., Sunka, P. 2005. Generation of ozone by

962 pulsed corona discharge over water surface in hybrid gas-liquid electrical discharge

963 reactor. Journal of Physics D: Applied Physics, 38(3), 409.

964 Magureanu, M., Mandache, N.B., Parvulescu, V.I. 2015. Degradation of pharmaceutical

965 compounds in water by non-thermal plasma treatment. Water Research,

966 81(Supplement C), 124-136.

967 Mahamuni, N.N., Adewuyi, Y.G. 2010. Advanced oxidation processes (AOPs) involving

968 ultrasound for waste water treatment: A review with emphasis on cost estimation.

969 Ultrasonics Sonochemistry, 17(6), 990-1003.

970 Massoud, M.A., Tarhini, A., Nasr, J.A. 2009. Decentralized approaches to wastewater

971 treatment and management: Applicability in developing countries. Journal of

972 Environmental Management, 90(1), 652-659.

973 Natarajan, T.S., Thomas, M., Natarajan, K., Bajaj, H.C., Tayade, R.J. 2011. Study on UV-

$974 \mathrm{LED} / \mathrm{TiO}_{2}$ process for degradation of Rhodamine B dye. Chemical Engineering

975 Journal, 169(1), 126-134.

976 Neumann, P., Pesante, S., Venegas, M., Vidal, G. 2016. Developments in pre-treatment

977 methods to improve anaerobic digestion of sewage sludge. Reviews in Environmental

978 Science and Bio/Technology, 15(2), 173-211.

$979 \mathrm{Ni}, \mathrm{X} .2006$. Continuous oscillatory baffled reactor technology. Innovations in

980 Pharmaceutical Technology, 20(90-96).

981 Ni, X., Cosgrove, J.A., Cumming, R.H., Greated, C.A., Murray, K.R., Norman, P. 2001.

982 Experimental study of flocculation of Bentonite and Alcaligenes eutrophus in a batch

983 oscillatory baffled flocculator. Chemical Engineering Research and Design, 79(1),

984 33-40.

985 Nielson, K., Smith, D.W. 2005. Ozone-enhanced electroflocculation in municipal wastewater 986 treatment. Journal of Environmental Engineering and Science, 4(1), 65-76.

987 Nikačević, N.M., Huesman, A.E.M., Van den Hof, P.M.J., Stankiewicz, A.I. 2012.

988 Opportunities and challenges for process control in process intensification. Chemical

989 Engineering and Processing: Process Intensification, 52(Supplement C), 1-15.

990 Ofwat. 2017. Water sector overview: https://www.ofwat.gov.uk/regulated-companies/ofwat$991 \quad$ industry-overview/. 
992 Owabor, E. 2013. Mass transfer: Impact of intrinsic kinetics on the environment. in: Mass

993

994

995

996

997

998

999

1000

1001

1002

1003

1004

1005

1006

1007

1008

1009

1010

1011

1012

1013

1014

1015

1016

1017

1018

1019

1020

1021

1022

1023

1024

1025 transfer - Advances in sustainable energy and environment oriented numerical modeling, (Ed.) H. Nakajima, InTech. Rijeka, pp. Ch. 18.

Patist, A., Bates, D. 2008. Ultrasonic innovations in the food industry: From the laboratory to commercial production. Innovative Food Science \& Emerging Technologies, 9(2), 147-154.

Petala, M., Tsiridis, V., Samaras, P., Zouboulis, A., Sakellaropoulos, G.P. 2006. Wastewater reclamation by advanced treatment of secondary effluents. Desalination, 195(1), 109118.

Peters, L. 2012. UV LEDs ramp up the quiet side of the LED market. in: LED Magazine, PennWell International Ltd: http://www.ledsmagazine.com/articles/print/volume9/issue-2/features/uv-leds-ramp-up-the-quiet-side-of-the-led-market-magazine.html

Phan, A.N., Harvey, A. 2010. Development and evaluation of novel designs of continuous mesoscale oscillatory baffled reactors. Chemical Engineering Journal, 159(1), 212219.

Ponce-Ortega, J.M., Al-Thubaiti, M.M., El-Halwagi, M.M. 2012. Process intensification: New understanding and systematic approach. Chemical Engineering and Processing: Process Intensification, 53(Supplement C), 63-75.

Qiu, Z., Zhao, L., Weatherley, L. 2010. Process intensification technologies in continuous biodiesel production. Chemical Engineering and Processing: Process Intensification, 49(4), 323-330.

Ramaswamy, H., Tang, J. 2008. Microwave and radio frequency heating. Food Science and Technology International, 14(5), 423-427.

Ramshaw, C. 1983. Higee distillation - an example of process intensification. Chemical Engineer 389, 13-14.

Rao, D.P., Bhowal, A., Goswami, P.S. 2004. Process intensification in rotating packed beds (HIGEE): An appraisal. Industrial \& engineering chemistry research, 43(4), 11501162.

Reay, D., Ramshaw, C., Harvey, A. 2013. Process intensification: engineering for efficiency, sustainability and flexibility. Butterworth-Heinemann.

Rehman, F., Medley, G.J.D., Bandulasena, H., Zimmerman, W.B.J. 2015. Fluidic oscillatormediated microbubble generation to provide cost effective mass transfer and mixing efficiency to the wastewater treatment plants. Environmental Research, 137(Supplement C), 32-39. 
1026 Remya, N., Lin, J.-G. 2011. Current status of microwave application in wastewater

1027

1028

1029

1030

1031

1032

1033

1034

1035

1036

1037

1038

1039

1040

1041

1042

1043

1044

1045

1046

1047

1048

1049

1050

1051

1052

1053

1054

1055

1056

1057

1058 treatment-A review. Chemical Engineering Journal, 166(3), 797-813.

Rosal, R., Rodríguez, A., Perdigón-Melón, J.A., Petre, A., García-Calvo, E., Gómez, M.J., Agüera, A., Fernández-Alba, A.R. 2010. Occurrence of emerging pollutants in urban wastewater and their removal through biological treatment followed by ozonation. Water Research, 44(2), 578-588.

Rosario-Ortiz, F., Rose, J., Speight, V., Gunten, U.v., Schnoor, J. 2016. How do you like your tap water? Science, 351(6276), 912-914.

Rosario-Ortiz, F., Speight, V. 2016. Can drinking water be delivered without disinfectants like chlorine and still be safe? in: The Converstation: https://theconversation.com/candrinking-water-be-delivered-without-disinfectants-like-chlorine-and-still-be-safe55476

Rosso, D., Larson, L.E., Stenstrom, M.K. 2008. Aeration of large-scale municipal wastewater treatment plants: state of the art. Water Science and Technology, 57(7), 973-978.

Ruan, J.-j., Li, W., Shi, Y., Nie, Y., Wang, X., Tan, T.-e. 2005. Decomposition of simulated odors in municipal wastewater treatment plants by a wire-plate pulse corona reactor. Chemosphere, 59(3), 327-333.

Schlegelmilch, M., Streese, J., Stegmann, R. 2005. Odour management and treatment technologies: An overview. Waste Management, 25(9), 928-939.

Shima, S. 2011. Microwave-powered UV disinfection for wastewater treatment. in: Water \& Wastes Digest, Scranton Gillette Communications.

Song, K., Mohseni, M., Taghipour, F. 2016. Application of ultraviolet light-emitting diodes (UV-LEDs) for water disinfection: A review. Water Research, 94(Supplement C), 341-349.

Speight, V.L. 2015. Innovation in the water industry: barriers and opportunities for US and UK utilities. Wiley Interdisciplinary Reviews: Water, 2(4), 301-313.

Spiller, M., McIntosh, B.S., Seaton, R.A.F., Jeffrey, P.J. 2015. Integrating Process and Factor Understanding of Environmental Innovation by Water Utilities. Water Resources Management, 29(6), 1979-1993.

Spiller, M., McIntosh, B.S., Seaton, R.A.F., Jeffrey, P.J. 2012. An organisational innovation perspective on change in water and wastewater systems - the implementation of the Water Framework Directive in England and Wales. Urban Water Journal, 9(2), 113128. 
1059 Stankiewicz, A.I., Moulijn, J.A. 2000. Process intensification: transforming chemical engineering. Chemical Engineering Progress, 96(1), 22-34.

1061 Taniyasu, Y., Kasu, M., Makimoto, T. 2006. An aluminium nitride light-emitting diode with 1062 a wavelength of 210[thinsp]nanometres. Nature, 441(7091), 325-328.

1063 Tanner, A.S., McIntosh, B.S., Widdowson, D.C.C., Tillotson, M.R. 2016. The water utility 1064 adoption model (wUAM): Understanding influences of organisational and procedural innovation in a UK water utility. Journal of Cleaner Production.

Tayalia, Y., Vijaysai, P. 2012. Process intensification in water and wastewater treatment systems. in: 11th International Symposium on Process Systems Engineering PSE2012, (Eds.) L.A. Karimi, R. Srinivasan, pp. 32-40.

Temesgen, T., Bui, T.T., Han, M., Kim, T.-i., Park, H. 2017. Micro and nanobubble technologies as a new horizon for water-treatment techniques: A review. Advances in Colloid and Interface Science, 246(Supplement C), 40-51.

Tesař, V., Hung, C.-H., Zimmerman, W.B. 2006. No-moving-part hybrid-synthetic jet actuator. Sensors and Actuators A: Physical, 125(2), 159-169.

Thomas, D.A. 2012. Don't just talk about water success, achieve it. in: Utility Week, Faversham House Group: http://utilityweek.co.uk/news/Dont-just-talk-about-watersuccess-achieve-it/820892\#.WX87SIjyvb0

Thomas, D.A., Ford, R.R. 2006. Barriers to innovation in the UK water industry. UK Water Industry Research. 06/RG/10/1.

Thomas, D.A., Ford, R.R. 2008. A written submission to the call for evidence of the Cave Review of competition and innovation in water markets.

Tixier, C., Singer, H.P., Oellers, S., Müller, S.R. 2003. Occurrence and fate of carbamazepine, clofibric acid, diclofenac, ibuprofen, ketoprofen, and naproxen in surface waters. Environmental Science \& Technology, 37(6), 1061-1068.

UKWIR. 2011. National sewer and water mains failure database, Issue 1.2. 08/RG/05/26. wastewater reverse osmosis concentrate using UVC-LED/H2O2 with and without ultrasound as water disinfection technology. Desalination and Water Treatment, 55(5), 1393-1399. 
1092 Wang, H., Mustaffar, A., Phan, A.N., Zivkovic, V., Reay, D., Law, R., Boodhoo, K. 2017a. A

1093

1094

1095

1096

1097

1098

1099

1100

1101

1102

1103

1104

1105

1106

1107

1108

1109

1110

1111

1112

1113

1114

1115

1116

1117

1118

1119

1120

1121

1122

1123

1124

1125 review of process intensification applied to solids handling. Chemical Engineering and Processing: Process Intensification, 118(Supplement C), 78-107.

Wang, H., Wang, Y., Lou, Z., Zhu, N., Yuan, H. 2017b. The degradation processes of refractory substances in nanofiltration concentrated leachate using micro-ozonation. Waste Management, 69(Supplement C), 274-280.

Wang, W., Zou, H.-K., Chu, G.-W., Weng, Z., Chen, J.-F. 2014. Bromination of butyl rubber in rotating packed bed reactor. Chemical Engineering Journal, 240(Supplement C), 503-508.

Wilinski, P., Robert, Naumczyk, J. 2012. Dissolved ozone flotation as a innovative and prospect method for treatment of micropollutants and wastewater treatment costs reduction. 12th edition of the World Wide Workshop for Young Environmental Scientists (WWW-YES-2012) - Urban waters: resource or risks?, 2012-05-21, Arcueil, France. HAL-ENPC.

Wu, T.Y., Guo, N., Teh, C.Y., Hay, J.X.W. 2013. Theory and fundamentals of ultrasound. in: Advances in Ultrasound Technology for Environmental Remediation, Springer Netherlands. Dordrecht, pp. 5-12.

Würtele, M.A., Kolbe, T., Lipsz, M., Külberg, A., Weyers, M., Kneissl, M., Jekel, M. 2011. Application of GaN-based ultraviolet-C light emitting diodes - UV LEDs - for water disinfection. Water Research, 45(3), 1481-1489.

Yang, H.-J., Chu, G.-W., Zhang, J.-W., Shen, Z.-G., Chen, J.-F. 2005. Micromixing efficiency in a rotating packed bed: Experiments and simulation. Industrial \& engineering chemistry research, 44(20), 7730-7737.

Yang, K., Chu, G., Zou, H., Sun, B., Shao, L., Chen, J.-F. 2011. Determination of the effective interfacial area in rotating packed bed. Chemical Engineering Journal, 168(3), 1377-1382.

Yuan, M.-H., Chen, Y.-H., Tsai, J.-Y., Chang, C.-Y. 2016. Removal of ammonia from wastewater by air stripping process in laboratory and pilot scales using a rotating packed bed at ambient temperature. Journal of the Taiwan Institute of Chemical Engineers, 60(Supplement C), 488-495.

Zeng, Z., Zou, H., Li, X., Sun, B., Chen, J., Shao, L. 2012. Ozonation of acidic phenol wastewater with $\mathrm{O}_{3} / \mathrm{Fe}(\mathrm{II})$ in a rotating packed bed reactor: Optimization by response surface methodology. Chemical Engineering and Processing: Process Intensification, 60, 1-8. 
1126 Zhang, L., Guo, X., Yan, F., Su, M., Li, Y. 2007. Study of the degradation behaviour of dimethoate under microwave irradiation. Journal of hazardous materials, 149(3), 675-679.

1129 Zhang, Y., Geißen, S.-U., Gal, C. 2008. Carbamazepine and diclofenac: Removal in

1130 wastewater treatment plants and occurrence in water bodies. Chemosphere, 73(8), 1131 1151-1161.

1132 Zhao, H., Shao, L., Chen, J.-F. 2010. High-gravity process intensification technology and 1133 application. Chemical Engineering Journal, 156(3), 588-593.

1134 Zhou, H., Smith, D.W. 2000. Ozone mass transfer in water and wastewater treatment: 1135 experimental observations using a 2D laser particle dynamics analyzer. Water $1136 \quad$ Research, 34(3), 909-921.

1137 Zimmerman, W.B., Hewakandamby, B.N., Tesař, V., Bandulasena, H.C.H., Omotowa, O.A. 1138 2009. On the design and simulation of an airlift loop bioreactor with microbubble generation by fluidic oscillation. Food and Bioproducts Processing, 87(3), 215-227.

1140 Zimmerman, W.B., Tesar̆, V., Bandulasena, H.C.H. 2011. Towards energy efficient nanobubble generation with fluidic oscillation. Current Opinion in Colloid \&

1143 Zimmerman, W.B., Tesar, V., Butler, S., Bandulasena, H.C.H. 2008. Microbubble Generation. Recent Patents on Engineering, 2(1), 1-8.

1145 Zou, H., Wang, L. 2017. The disinfection effect of a novel continuous-flow water sterilizing system coupling dual-frequency ultrasound with sodium hypochlorite in pilot scale. Ultrasonics Sonochemistry, 36(Supplement C), 246-252. 